\title{
FORMAÇÃO DE PROFESSORES OUVINTES NO PROCESSO DE ENSINO-APRENDIZAGEM DE ALUNOS SURDOS
}

\author{
ARTIGO ORIGINAL \\ MOURA, Anaisa Alves de ${ }^{1}$ \\ COSTA, Bruno Ismael Diogo da ${ }^{2}$ \\ SILVA, Graça Maria de Morais Aguiar e ${ }^{3}$ \\ MOURA, Vithória Alves de ${ }^{4}$
}

${ }^{1}$ Doutoranda em Educação - ULHT - Lisboa/Portugal (2018). Mestre em Ciências da Educação. Especialista em Gestão Escolar, Educação Especial, Educação a Distância, Psicopedagogia Institucional, Clínica e Hospitalar e Licenciada em Pedagogia. Professora pesquisadora pela CAPES desde 2013. Atualmente integra 0 grupo de Estudos e Pesquisas Narrativas Autobiográficas do CNPq.

${ }^{2}$ Especialista em Libras pela Faculdade Evangélica do Piauí - FAEPI. Licenciado em Letras com habilitação em Língua Inglesa pela Universidade Estadual Vale do Acaraú - UVA. Professor e coordenador na Escola José Martins de Sousa - Alcântaras - CE. ${ }^{3}$ Doutoranda em Educação - ULHT - Lisboa/Portugal (2018). Mestre em Educação e Formação de Professores com foco em Educação Inclusiva. Especialista em Tutoria e Educação a Distância e Docência no Ensino Superior (UNINTA) e Graduada em Pedagogia pela Universidade Estadual Vale do Acaraú - UVA. Atualmente é professora e Pró-Reitora de Desenvolvimento Institucional no Centro Universitário UNINTA e responde como Procuradora Institucional.

${ }^{4}$ Acadêmica do curso de Psicologia do $8^{\circ}$ semestre pela Faculdade Luciano Feijão (FLF) - Sobral-CE. Linha de pesquisa voltada para a temática Transtorno do Espectro Autista (TEA) no âmbito escolar. 
MOURA, Samile Alves de ${ }^{5}$

MOURA, Anaisa Alves de. Et al. Formação de professores ouvintes no processo de ensino-aprendizagem de alunos surdos. Revista Científica Multidisciplinar Núcleo do Conhecimento. Ano 05, Ed. 05, Vol. 02, pp. 117-130. Maio de 2020. ISSN: 2448-0959, Link de acesso: https://www.nucleodoconhecimento.com.br/educacao/alunos-surdos

\section{RESUMO}

O presente artigo tem como objetivo principal discutir a importância da formação dos professores na utilização da Língua Brasileira de Sinais - Libras, na ótica da educação inclusiva, que se baseia no decreto no 5.626/05 e que dispõe sobre a obrigatoriedade da disciplina de Libras na grade curricular de cursos de licenciatura, bem como entender a atuação docente no processo de ensino-aprendizagem e destacar a importância da referida língua no contexto da educação bilíngue. A Lei no 10.436/02 nos mostra que a Libras pertence a comunidade surda, todavia há algumas dificuldades, como a falta de formação de professores ouvintes, o despreparo destes profissionais no atendimento das necessidades dos alunos surdos e a carência de metodologias adequadas no processo de ensino-aprendizagem. Utilizou-se como metodologia exclusivamente a pesquisa bibliográfica, por meio de pesquisas em revistas científicas, artigos, dissertações, teses e livros, considerando a análise teórica de autores como Menezes (2006), Pereira (2000), Quadros (2000), Sánchez (1989), Gallagher (1996), Antunes (2012) , Libâneo (1998), entre outros. Ao término deste estudo conclui-se que a formação de professores ouvintes é fundamental no processo de aprendizagem de alunos surdos para que haja de fato uma educação inclusiva e igualitária para esta comunidade.

\footnotetext{
${ }^{5}$ Acadêmica do curso de Serviço Social do $8^{\text {o }}$ semestre pela Universidade Norte do Paraná - UNOPAR - Pólo Sobral-CE. Linha de pesquisa voltada para os grupos de riscos e vulnerabilidade. Atualmente é Auxiliar de Pessoal - IGS - Instituto para Gestão em Saúde.
} 
Palavras-chave: Libras, ensino-aprendizagem, surdos, formação, professores ouvintes.

\section{INTRODUÇÃO}

No âmbito atual da educação brasileira a escola deve ser o local de promoção de desenvolvimento se seus alunos, sem distinção, bem como do respeito à diversidade e as particularidades dos seus alunos na sua prática pedagógica. Portanto, é de fundamental importância um estudo que discuta o processo de ensino-aprendizagem da Língua Brasileira de Sinais, tendo como foco a preparação dos educadores para a atuação de práticas pedagógicas com alunos surdos a fim de que esses profissionais entendam o seu papel e possam assim oferecer um ensino de qualidade para seus alunos.

Com base nesta perspectiva, esse artigo objetiva analisar aspectos referentes à importância da qualificação dos professores ouvintes no processo de ensinoaprendizagem de alunos surdos, por meio da Língua Brasileira de Sinais - Libras sob a ótica do bilinguismo. Outro aspecto ressaltado é a obrigatoriedade da referida língua em cursos de licenciatura, fato esse que significou uma grande conquista para a comunidade surda.

Ao nos referirmos à prática pedagógica dos professores no processo de ensino e aprendizagem é importante ressaltar a importância da utilização da Libras no ambiente educacional como L1, para que posteriormente seja inclusa a Língua Portuguesa como L2 para os discentes surdos, pressuposto que está presente na lei 10.436 e dispõe sobre a atuação e formação dos professores no ensino de Libras. Porém sabemos que na prática, há muitos fatores que dificultam o desenvolvimento de uma educação de qualidade para os alunos surdos. Um deles é a utilização da mesma metodologia de alunos ouvintes para os surdos: aulas expositivas e explicativas no quadro, o que é resultante do despreparo de professores para lidar com este público e que ao invés de incluir acarreta o crescimento da inclusão dos referidos alunos, o que leva o estudo a levantar a seguinte problemática: quais os 
prejuízos que a ausência da utilização da Libras pode causar na aprendizagem dos alunos surdos?

Assim, incluir alunos surdos na escola regular requer um grande cuidado e implica desafios aos educadores, sobretudo na interação e comunicação com este público. Para que se possa fornecer os subsídios necessários à aprendizagem é preciso conhecer a identidade surda, suas especificidades para que se alcancem metodologias de ensino que promovam o desenvolvimento pleno nos aspectos sociais e culturais. A este respeito, Saviani afirma que

Para debater e apresentar as informações, este estudo constitui-se em Revisão Bibliográfica através de fontes como: livros, artigos, trabalhos acadêmicos, revistas científicas, sites e outras que discutem o tema, em que se destacam as considerações teóricas do autor citado acima, bem como de autores como Menezes (2006), Pereira (2000); Quadros (2000), Sánchez (1989); Gallagher (1996); Antunes (2012), Libâneo (1998), entre outros.

A motivação para a realização deste trabalho se deve ao desejo profissional do autor em atuar no ensino de alunos surdos utilizando a Libras como a língua de mediação com o objetivo de oferecer uma aprendizagem significativa para o público-alvo, pautando-se na educação bilíngue.

Para tanto, o artigo foi assim dividido: inicialmente o resumo, logo após a introdução, dando continuidade, abordou-se sobre a Língua Brasileira de Sinais; em seguida a importância desta língua para a aprendizagem dos surdos na escola regular e o papel do professor no processo de ensino-aprendizagem. Logo em seguida debateu-se sobre o bilinguismo na educação do surdo para posteriormente comentar sobre o ensino da Língua Portuguesa para alunos surdos e a importância da Libras na formação de professores. Por fim, apresentou-se a obrigatoriedade da Libras nos cursos de licenciatura, seguido das considerações finais e referências bibliográficas. 


\section{A LÍNGUA BRASILEIRA DE SINAIS-LIBRAS}

A Lei oㅜ 10.436, de 24 de abril de 2002 dispõe sobre a Língua Brasileira de Sinais Libras, reconhecendo-a como meio de comunicação e expressão para a comunidade surda, em que afirma:

Entende-se como Língua Brasileira de Sinais - Libras a forma de comunicação e expressão em que o sistema linguístico de natureza visual-motora, com estrutura gramatical própria, constitui um sistema linguístico de transmissão de ideias e fatos, oriundos de comunidades de pessoas surdas do Brasil. [...]

Art. $2^{\circ}$ - Deve ser garantido, por parte do poder público em geral e empresas concessionárias de serviços públicos, formas institucionalizadas de apoiar o uso e difusão da Língua Brasileira de Sinais - Libras como meio de comunicação objetiva e de utilização corrente das comunidades surdas do Brasil. (BRASIL, 2002)

É importante conhecermos a trajetória histórica da Libras e seu surgimento. A respeito disso Menezes (2006) menciona que o Brasil ainda era uma colônia portuguesa governada pelo imperador Pedro Il quando a Língua de Sinais para surdos aportou no país, mais precisamente no Rio de Janeiro.

Em 1856, o conde francês Ernest Huet desembarcou na capital fluminense com o alfabeto manual francês e alguns sinais. O material trazido pelo conde, que era surdo, deu origem à Língua Brasileira de Sinais (Libras). O primeiro órgão no Brasil a desenvolver trabalhos com surdos e mudos surgiu em 1857. Foi do então Instituto dos Surdos-Mudos do Rio de Janeiro, hoje Instituto Nacional de Educação de Surdos (INES), que saíram os principais divulgadores da Libras. A iconografia dos sinais, ou seja, a criação dos símbolos, só foi apresentada em 1873, pelo aluno surdo Flausino José da Gama. Ela é o resultado da mistura da Língua de Sinais Francesa com a Língua de Sinais Brasileira antiga, já usada pelos surdos das várias regiões do Brasil. 
A Libras desempenha uma importante função cognitiva e estrutural para seus falantes, portanto, na visão de Pereira (2000), a língua de sinais preenche as mesmas funções que a linguagem falada tem para os ouvintes. Como ocorre com crianças ouvintes, espera-se que a língua de sinais seja adquirida na interação com usuários fluentes da mesma, os quais, envolvendo as crianças surdas em práticas discursivas e interpretando os enunciados produzidos por elas, insiram-se no funcionamento dessa língua.

A Língua Brasileira de sinais desempenha também o papel na aquisição da leitura e da escrita, uma vez que possibilitará aos surdos o conhecimento de mundo e fará com que eles compreendam o que leem, tornando-os mais que meros decodificares de sinais. Skliar (1997) argumenta que faz-se necessário um modelo no qual o déficit auditivo não cumpra nenhum papel relevante, um modelo que se origine e se justifiquem nas interações normais e habituais dos surdos entre si, no qual a língua de sinais seja o traço fundamental de identificação sociocultural e no qual o modelo pedagógico não seja uma obsessão para corrigir o déficit, mas a continuação de um mecanismo de compensação que os próprios surdos, historicamente, já demonstraram utilizar.

\subsection{A IMPORTÂNCIA DO ENSINO DA LIBRAS NA APRENDIZAGEM DOS SURDOS NA ESCOLA REGULAR}

Muitas são as discussões a respeito do ensino da Língua Brasileira de Sinais na escola regular e o papel da escola e de todos os envolvidos no processo de ensinoaprendizagem neste contexto. Com relação a este aspecto Ferrão e Lobato (2016) mencionam que as escolas precisam se organizar para ter um ambiente com um contexto linguístico adequado para os Surdos, buscando um êxito na sua educação, para isso as escolas deve perceber que a língua de sinais, sendo a língua oficial da comunidade surda, seja uma garantia de direito do surdo usar sua língua natural.

Ainda segundo os referidos autores a falta de qualificação profissional dos educadores faz com que eles se sintam despreparados para atuar no processo de ensino para alunos surdos, fato esse que dificulta o aprendizado destes alunos. Para eles dentre 
as propostas educacionais para a melhoria da escolarização de Surdos está a formação do professor, porém, não é simples qualificar professores, sobretudo, no contexto sócio-político vigente. O professor questiona a falta de espaço e recursos materiais apropriados; a necessidade de um corpo técnico suficiente e uma remuneração adequada, a fim de que possa manter-se atualizado e qualificado

Portanto, torna-se fundamental a inserção da Libras no processo educacional dos surdos, o que implica, segundo Domingos (2014, p. 77) "no seu desenvolvimento e progresso linguístico e cognitivo, na facilidade da aprendizagem das línguas orais; em melhor leitura e compreensão de textos escritos e no favorecimento significativo à sua produção escrita".

\subsection{O PAPEL DO PROFESSOR}

O professor tem um papel de extrema importância no processo de ensinoaprendizagem do aluno surdo. A esse respeito é importante ressaltar que o professor deve ser capaz de conceber-se como agente de mudanças do contexto social, já que seu papel extrapola o mero repasse de conhecimentos, sendo, sobretudo, o de formar de cidadãos. "Sua atuação está comprometida com as condições da escola e com a qualidade de sua formação acadêmica. É ele, o professor, a autoridade responsável pelo processo de ensino - aprendizagem de seus alunos" (MEC 1993, apud PIRES, 2005, p. 15).

No que diz respeito a capacitação do professor para o ensino de Libras aos alunos surdos, é importante que este, ao apropriar-se deste contexto, de acordo com Motta e Gediel (2016, p. 59-60) "possua habilidade de construir metodologias apropriadas para o alcance do propósito de ensino e aprendizagem considerando a diferença cultural entre ouvintes e Surdos no espaço educacional".

Portanto, é fundamental que os professores conheçam e estimulem o uso da Libras no processo de ensino-aprendizagem dos surdos. 


\section{O BILINGUISMO NA EDUCAÇÃO DO ALUNO SURDO}

O bilinguismo traz como pressuposto principal a necessidade do surdo se tornar bilíngue, ou seja, se apropriar da língua de sinais como língua materna (L1) e a língua oral utilizada no seu país de origem como segunda língua (L2). Nessa perspectiva, Damázio (2007) afirma: "A abordagem educacional por meio do Bilinguismo visa capacitar a pessoa com surdez para a utilização de duas línguas no cotidiano escolar e na vida social [...]".

Ainda no que tange à inserção do bilinguismo na escola regular acrescenta Moura (1996 apud Gonçalves; Festa, 2013, p. 98) que "as formas específicas de ver, perceber, estabelecer relações e valores do Surdo devem ser utilizadas na sua educação, que somadas ao conjunto cultural ouvinte resultam na sua própria sociedade".

Há, no entanto, divergências com relação à inserção do aluno surdo na escola regular, pois para muitos essa comunidade fica a margem do processo de aprendizagem, fato esse que contribui para a exclusão social. Já outros acreditam que quando o aluno passa a ter contato com o ambiente da escola regular e convive com outros alunos ele se desenvolve cognitivamente.

Sobre a divergência citada acima, Quadros (2000, p.54) afirma que "Quando me refiro ao bilinguismo, não estou estabelecendo uma dicotomia, mas sim reconhecendo as línguas envolvidas no cotidiano dos surdos, ou seja, a Língua Brasileira de Sinais e o Português no contexto mais comum do Brasil."

Em se tratando da educação bilíngue para alunos surdos, torna-se evidente que todos os membros da comunidade escolar estejam cientes de seus papeis no processo de ensino-aprendizagem. Porém, para que isso ocorra, é preciso que haja qualificação dos educadores, pois como afirma Albres (2010 apud Martins, 2012, p. 99): "há a necessidade da formação do professor de Libras, [...], de professores especializados no ensino da Língua Portuguesa, como segunda língua para pessoas surdas [...]" 
Nesse sentido, Lerner (2002, p. 65) acrescenta que "o desafio que a escola enfrenta hoje é conseguir que todos os seus alunos cheguem a serem membros plenos da comunidade de leitores e escritores"

\section{O ENSINO DE LÍNGUA PORTUGUESA PARA ALUNOS SURDOS}

$\mathrm{Na}$ maioria das vezes, o ensino da Libras para alunos surdos na escola regular acontece utilizando-se a mesma metodologia aplicada aos ouvintes, com os mesmos materiais, restringindo assim o conhecimento da Língua Portuguesa ao estudo de vocabulário reduzido e frases feitas. A respeito desse pressuposto Terzi (1995, p. 51) comenta que: "(...) a ênfase na decodificação das palavras independente do seu significado cria, na escola, uma pseudo linguagem para falar da escrita, produzindo uma ruptura tanto no desenvolvimento da linguagem oral do aluno, como na linguagem escrita."

Para que os alunos surdos escrevam e leiam adequadamente, torna-se necessário que eles tenham conhecimentos de mundo, para que restabeleçam uma contextualização com o escrito e assim derivem o sentido. Com relação à leitura dos alunos surdos Friães e Pereira (2000) argumentam que o aluno surdo tem muita dificuldade de ler faz com que os professores evitem a atividade e, assim, a leitura vai se tornando cada vez mais difícil, limitando-se a textos pequenos, facilitados, tanto semântica como sinteticamente, empobrecidos e, muitas vezes, não adaptados ao interesse dos alunos.

Muitos profissionais da educação acreditam que os surdos aprendam por meio de estruturas lexicais mais simples, para gradativamente progredirem para um nível mais avançado de estruturas. Porém, como afirma Sánchez (1989, p. 125) (...) "os surdos, de forma diferente que os ouvintes, não podem aprender o som das letras porque não ouvem e não podem fazer uso do mecanismo alfabético para extrair significado do escrito".

Ao analisarmos essa citação fica evidente que o ensino da língua portuguesa seja inserido no processo de alfabetização de crianças surdas, pois desta forma elas terão 
contato com a língua de forma funcional, a partir de objetos conhecidos por elas as mesmas farão a associação entre imagem e palavra. Sobre essa associação Moreira (2017, p. 133) "o reconhecimento da existência de uma segunda língua é fortalecido nas associações feitas pelas crianças por meio de situações visuais (imagens ou sinais, signos em Libras)."

Neste contexto, o professor ganha um novo papel, como pontua Pereira (2014), argumentando que o professor deixa de ocupar o papel principal no processo de ensino-aprendizagem, de detentor do conhecimento, para assumir o papel de parceiro, ajudando cada aluno a progredir na aprendizagem. Logo, a partir dos conhecimentos prévios com relação a L1 dos alunos surdos (A Língua Brasileira de Sinais) o professor irá embasar sua prática pedagógica.

Ainda sobre o papel do professor na aquisição da língua portuguesa para os surdos, na visão de Gatti (2014) o professor certamente tem papel decisivo a desempenhar nesse cenário o da possibilidade de ajudar na construção de uma civilização humana de bem-estar para todos".

\subsection{A IMPORTÂNCIA DA LIBRAS NA FORMAÇÃO DE PROFESSORES}

Diante da educação inclusiva, que busca a promoção de uma escola igualitária, onde todos tenham acesso ao ensino, torna-se evidente a necessidade da inclusão da Língua Brasileira de Sinais na formação dos educadores, para que esses profissionais direcionem a sua prática pedagógica na diversidade humana e cultural.

Tal afirmação está presente na Resolução do CNE/CEB em seu artigo 2ํ․

Os sistemas de ensino devem matricular todos os alunos, cabendo às escolas organizarem-se para o atendimento aos educandos com necessidades especiais, assegurando as condições necessárias para uma educação de qualidade para todos (BRASIL, 2001, p. 15).

Moran (2013, p. 33) acrescenta que "a educação de qualidade é uma educação inovadora, aberta, dinâmica, participativa, que integra docentes bem preparados, e 
que visa o atendimento diferenciado ao educando, em que habilidades e limitações são observadas e analisadas"

A Libras desempenha um papel de fundamental importância, pois juntamente com a cultura surda é um elemento norteador na construção da prática pedagógica dos educadores. Portanto, para que possa fornecer os subsídios necessários à aprendizagem dos alunos, os professores deverão ter domínio das estruturas lexicais e estruturais da referida língua, bem como de metodologias diversificadas para atender as especificidades de cada aluno, como nos afirmam Vitaliano, Maria Canazza, Dall"Acqua, Sonia Dechandt (2010) "O processo de inclusão dos alunos Surdos nas classes comuns do ensino regular imprime a necessidade dos professores dominarem minimamente a Libras"

Muitas pessoas têm uma visão errônea com relação a Libras pelo fato de acreditarem que essa língua é composta apenas por gestos ou mímicas: Para Ray Jackendoff (1994 apud PIZZIO; QUADROS; REZENDE, 2009, p.9)

A coisa mais importante que eu quero destacar é que ASL é uma língua. Claro, ela parece ser completamente diferente de outras línguas já conhecidas como o inglês, o russo e o japonês. Isso significa que a transmissão não é através do trato vocal criando sinais acústicos que são detectados pelo interlocutor por meio da audição. Ao invés disso, os gestos do sinalizador criam sinais que são detectados pelo interlocutor por meio do sistema visual. [...] O sistema periférico é diferente, mas a atividade inerente é a mesma (JACKENDOFF 1994 apud PIZZIO; QUADROS; REZENDE, 2009, p.9)

A partir dessa afirmação percebemos que a Libras é mais que uma mera língua de gestos é uma língua com estrutura lexical e estrutural própria, de natureza visual e gestual. 


\section{A OBRIGATORIEDADE DA LIBRAS NOS CURSOS DE LICENCIATURA}

Os professores precisam estar preparados para lidar com alunos surdos, mas muitos ainda utilizam metodologias tradicionais por meio de aulas expositivas e explicativas no quadro. Segundo Antunes (2012, p. 79) "O professor precisa pensar em estratégias que contemplem a percepção visual do aluno Surdo; compreender a cultura em que esse sujeito está inserido; entender como ele assimila o conteúdo".

Já James Gallagher (1996) nos chama atenção para o fato do processo de ensinoaprendizagem de crianças surdas ficar comprometido e eles apresentarem dificuldades em produzir a linguagem que é imposta a ele, portanto, as crianças com deficiência auditiva apresentam alguns dos problemas mais difíceis e desafiantes para a educação especial. A perda auditiva interfere tanto na recepção da linguagem quanto na sua produção. Pelo fato de a linguagem interferir em praticamente todas as dimensões do desenvolvimento, a incapacidade de ouvir e falar é uma deficiência crítica, que pode dificultar o ajustamento social e acadêmico.

O Decreto Presidencial no 5626/2005, regulamentou, além de outras ações, a questão do ensino da Libras como disciplina obrigatória nos cursos de formação de professores.A respeito desta inclusão Cunha (2007) menciona que no sentido de sanar essa deficiência de professores linguisticamente capacitados, políticas públicas passam a entrar em vigor de modo a garantir que a Língua Brasileira de Sinais efetivamente funcione "como meio de comunicação objetiva e de utilização corrente das comunidades Surdas do Brasil", conforme expresso na Lei №. 10.436, de 2002.

Baseado na afirmação acima se torna evidente que além da inclusão da Libras nos cursos de licenciatura torna-se necessário a preparação dos docentes na atuação do ensino de alunos surdos, sobretudo para professores ouvintes, como ressalta Deonísio Schmitt (2008, p. 39) "[...] é preciso expandir o curso de Língua de Sinais nas escolas [...] para que os ouvintes entendam a cultura Surda, identidade e movimentos Surdos." 
Através do decreto no 5.626/2005, tomamos conhecimento das instituições em que a Língua Brasileira de Sinais deverá ser um componente curricular obrigatório:

Art. 3ำ A Libras deve ser inserida como disciplina curricular obrigatória nos cursos de formação de professores para o exercício do magistério, em nível médio e superior, e nos cursos de Fonoaudiologia, de instituições de ensino, públicas e privadas, do sistema federal de ensino e dos sistemas de ensino dos Estados, do Distrito Federal e dos Municípios (BRASIL, 2005, 34).

Já para os outros cursos, a Libras deverá ser ofertada de forma eletiva, conforme dispõe a legislação:

Art. $2^{\circ}$ A Libras constituir-se-á em disciplina curricular optativa nos demais cursos de educação superior e na educação profissional, a partir de um ano da publicação deste Decreto (BRASIL, 2005, p. 33).

$\mathrm{Na}$ perspectiva da inclusão escolar de alunos com Necessidades Educacionais Especiais (NEE), Almeida e Vitaliano (2012) menciona a grande importância da formação de professores na Llbras e não se pode mais ignorar as diferentes condições de aprendizagem dos alunos que integram o sistema de ensino, de modo a proporcionar-lhes uma educação de qualidade.

Conforme as autoras citadas acima a ênfase é dada apenas na inclusão dos alunos surdos na escola, mas não na qualidade do ensino que é dado a eles. Portanto Ferreira (2003) acrescenta que o sujeito Surdo não é apenas de ordem biológica, como se costuma pensar. É de ordem linguística e, portanto, cultural. Não se pode negar que o Surdo tenha uma deficiência auditiva. Entretanto, quando amparado pela aparelhagem adequada, ele pode ouvir ruídos da rua, música, etc. Porém, não ouve com a devida nitidez os sons da língua "oral" e não conta com o feedback linguístico, tão importante no processo de aquisição de uma língua. $E$ o atraso no desenvolvimento linguístico acarreta atraso no desenvolvimento cognitivo. 
Ainda no que diz respeito qualidade na educação dos surdos Brzezinski (2008) nos apresenta o conceito de qualidade social. De acordo com suas palavras ela

[...] fundamentada na concepção histórico-social e que tem como paradigma educacional as relações entre cultura, sociedade e educação [...] sendo o processo marcado pela complexidade do conhecimento, pela crítica, pela reflexão-ação, pela criatividade, pelo reconhecimento da identidade dos envolvidos nos processos e pelas relações estabelecidas na mediação entre formadores e aprendentes (BRZEZINSKI, 2008, p. 1141-1142).

De acordo com a citação acima, percebe-se a importância da mudança do contexto educacional em que a comunidade está inserida, através da reflexão sobre a identidade cultural e social desta população, porém, é sabido que existem documentos que amparam a educação dos surdos, que é composto pelo conjunto de leis denominado Políticas Públicas e sua implementação, há um grande fosso.

Com as políticas públicas educacionais na área de educação de Surdos, não é diferente. Há lei para acessibilidade que garante intérprete de Língua de Sinais/Língua Portuguesa durante as aulas, flexibilidade na correção das provas escritas, materiais de informação aos professores sobre as especificidades do aluno Surdo etc. Mas, na prática, o que se percebe, é o aluno Surdo mais excluído do que incluído nas salas de aula regulares, enfrentando dificuldades, que, muitas vezes os seus familiares é que tentam minimizar, buscando soluções nem sempre eficientes para ajudá-los. Por outro lado, professores, em sua maioria, sem conhecimento mínimo da Libras e, algumas vezes, subsumido por uma carga horária de trabalho exaustiva, não têm tempo para buscar uma formação continuada na área.

Há uma grande lacuna entre os documentos legais que amparam a educação dos surdos e as políticas públicas necessárias as suas implementações. Elas afirmam também que, na maioria das vezes a inclusão dos surdos no processo educacional acaba gerando ainda mais exclusão destes na sociedade. 
Segundo Libâneo (1998, p. 79), a "formação continuada contribui para uma ação reflexiva dos professores", pois é através dela que os educadores irão repensar sua prática pedagógica, contribuindo dessa forma para uma melhoria das atividades desenvolvidas no contexto escolar. A esse respeito, Behrens (1996, p. 91) acrescenta que "Na busca da educação continuada é necessário ao profissional que acredita que a educação é um caminho para a transformação social"

\section{CONSIDERAÇÕES FINAIS}

Ao término desta pesquisa pode-se concluir que a formação de professores ouvintes para o processo de ensino-aprendizagem de alunos surdos é de fundamental importância, uma vez que a maioria destes profissionais não está preparada para lidar com esse público e muitas vezes aplicam atividades metodológicas iguais às dos alunos ouvintes.

Outro ponto a ser destacado é a relevância da Língua Brasileira de Sinais, que deverá ser inclusa no processo educacional dos surdos como L1 para posteriormente a língua portuguesa ser considerada como L2.

Evidenciou-se, a partir da análise teórica dos autores estudados que a falta da utilização da Libras no sistema de ensino regular de alunos surdos acarreta prejuízos no processo de ensino-aprendizagem destes alunos. Esses danos poderiam ser evitados se houvesse um maior engajamento dos profissionais da educação para com esse tipo de formação, caracterizando, assim, a relevância da presença de professores capacitados nos ambientes escolares que acolhem alunos surdos.

Portanto, diante da análise realizada sobre o tema em estudo afirma-se que os objetivos propostos por esse trabalho foram alcançados e que a intensão do autor em adquirir maiores informações acerca do tema estudado foi completada. Porém reiterase que a conclusão deste artigo não se encerra em si as observações referentes ao processo de ensino-aprendizagem da Língua Brasileira de Sinais no ensino regular. 
Espera-se, pois, que este estudo faça com que os professores ouvintes que atendem a alunos surdos possam se motivar para se qualificarem na referida língua para que de fato haja a inclusão destes alunos.

\section{REFERÊNCIAS}

ALMEIDA, J. J. F; VITALIANO, C. R. A Disciplina de Libras na Formação Inicial de Pedagogos: Experiência dos Graduandos. In: IX Seminário de pesquisa em educação da região Sul, 2012, Caxias do Sul. Anais do IX ANPED SUL, 2012. Disponível

em: http://www.ucs.br/etc/conferencias/index.php/anpedsul/9anpedsul/paper/viewFile/242 9/582 Acesso em: 03 de abril de 2020.

BEHRENS, M. A. Formação continuada dos professores e a prática pedagógica. Curitiba, PR: Champagnat, 1996.

BRASIL. Constituição da República Federativa do Brasil. Brasília: Senado Federal, 1988.

BRASIL. Decreto n. $\mathbf{5 . 6 2 6}$ de 22 de dezembro 2005. Regulamenta a Lei no 10.436, de 24 de abril de 2002, que dispõe sobre a Língua Brasileira de Sinais - Libras, e o art. 18 da Lei no 10.098, de 19 de dezembro de 2000. Disponível em: Acesso em 08 de abril de 2020.

BRASIL. Decreto n. 5.626, de 22 de dezembro de 2005. Regulamenta a Lei no 10.436, de 24 de abril de 2002, que dispõe sobre a Língua Brasileira de Sinais Libras, e o art. 18 da Lei no 10.098, de 19 de dezembro de 2000. Diário Oficial [da República Federativa do Brasil], Brasília, DF, 2005.

. Ministério da Educação. Resolução CNE/CEB, de 11 de setembro de 2001. Institui Diretrizes nacionais para a educação especial na educação básica. Secretaria de Educação Especial-SEESP, 2001. Disponível em: http://portal.mec.gov.br/cne/arquivos/pdf/CEB0201. Acesso em: 03 de abril de 2020. 
BRZEZINSKI, I. Políticas Contemporâneas de Formação de Professores para os anos iniciais do ensino fundamental. Educação Sociologia, Campinas: vol.29. n.105. 2008. p. 1139-1166.

CUNHA, P. M. A. Cenas do atendimento especial numa escola bilíngue: os discursos sobre a surdez e a produção de redes de saber-poder. In: QUADROS, R.M. de; PERLIN, G. (Org.). Estudos Surdos II. Petrópolis: Arara Azul, 2007. p. 38-85.

DAMÁZIO, Mirlene Ferreira Macedo. Educação Escolar de Pessoa com Surdez: Uma Proposta Inclusiva. 2005. 122f. Tese (Doutorado em educação) - Universidade Estadual de Campinas, Campinas, 2005. Disponível em: repositorio.unicamp.br/handle/REPOSIT/252979 . Acesso em: 12 de março de 2020.

FERRÃO, Cleomárcio Pereira; LOBATO, Huber Kline Guedes. A inclusão do aluno surdo no ensino regular na perspectiva de professores do ensino fundamental. In: diálogos sobre inclusão escolar e ensino-aprendizagem da Libras e Língua portuguesa como segunda língua para surdos. 2016. Acesso em: 12 de março de 2020.

FERREIRA, L. Legislação e a língua brasileira de sinais. São Paulo: Ferreira e Bergoncci Consultorias e Publicações, 2003.

FRIÃES, H.S.; PEREIRA, M. C. C. Compreensão da leitura e surdez. In: LACERDA, C.B. F. de; GÓES, M. C. R. surdez: processos educativos e subjetividade. São Paulo: Lovise, 2000. p. 113-122.

GATTI, B. A. A formação inicial dos professores para educação básica: as licenciaturas. Revista USP, São Paulo. № 100, p. 33-46. Dezembro/janeiro/fevereiro, 2013-2014.

KIRK, S. A.; GALLAGHER, J. J. Educação da criança excepcional. São Paulo: Martins Fontes, 1996. 
LERNER, D. Ler e escrever na escola: o rela, o possível e o necessário. Porto Alegre: Artmed, 2002.

LIBÂNEO, J. C. Adeus Professor, Adeus Professora? Novas exigências educacionais e profissões docentes. São Paulo: Cortez, 1998.

MARTINS, Vanessa Regina de Oliveira. O acontecimento do ensino de Libras diferenças e resistências. In: Libras e estudo: ensino-aprendizagem. 2012. Acesso em 20 de março de 2020.

MENEZES, E. T.; SANTOS, T. H. Libras (Língua Brasileira de Sinais). Dicionário Interativo da Educação Brasileira. Educa Brasil. São Paulo: Midiamix, 2006.

MORAN C. J. M. Os desafios de educar com qualidade. In: MORAN C. J. M.; MASETTO, M.; BEHRENS, M. (Org.). Novas tecnologias e mediação pedagógica. 21. ed. Campinas: Papirus editora, 2013, v.1, p. 21-24.

MOTTA, Janayna Avelar; GEDIEL, Ana Luisa Borba. Formação de professores em Libras: um caminho para a inclusão escolar. Diálogos entre culturas e sociedade. anais da I jornada de estudos linguísticos e literários. Acesso em 08 de março de 2020.

PEREIRA, M.C.C. Aquisição da língua portuguesa por aprendizes surdos. In: Seminário: Desafios para o próximo milênio. Rio de Janeiro: INES, Divisão de Estudos e Pesquisas, 2000. p.95-100.

PIZZIO, A. L. ; QUADROS, R. M. de ; REZENDE, P. L. F. Língua Brasileira de Sinais I. Florianópolis/SC: UFSC, 2009 (Material didático para Disciplina de Libras I).

QUADROS, R.M. de. Alfabetização e o ensino da língua de sinais. Textura, Canoas no 3 , p.54, 2000

SÁNCHEZ,C. La adquisición de la língua escrita sinmediación lingua oral. Caracas: OEA, 1989. 
SCHMITT, D. Espaço de conforto linguístico/cultural dos surdos na UFSC. In: QUADROS, R. M. (Org.). Estudos Surdos III. Petrópolis: Arara Azul, 2008.

SKLIAR, C. Uma perspectiva sócio-histórica sobre a psicologia e a educação dos surdos. In (org) Educação e exclusão: abordagens sócio antropológicas em educação especial. Porto Alegre: Editora Mediação, 1997.

TAVARES, I. M. S.; CARVALHO, T. S. S. Inclusão escolar e a formação de professores para o ensino de Libras (Língua Brasileira de Sinais): do texto oficial ao contexto. In: V Encontro de pesquisa em educação em Alagoas - 2010, Maceió. Anais do V Encontro de Pesquisa em Educação em Alagoas, 2010.

TERZI, S.B. A construção da leitura. Campinas: Ed Unicamp, 1995. A importância da capacitação em Libras de professores ouvintes no processo de ensinoaprendizagem de alunos surdos.

VITALIANO, C. R. Concepções de professores universitários da área de educação e do ensino regular sobre a integração de alunos especiais e a formação de professores. 2002. Tese. (Doutorado em Educação) - Universidade Estadual Paulista Júlio de Mesquita Filho, Marília. 2002.

Enviado: Abril, 2020.

Aprovado: Maio, 2020. 